\title{
Characterizing a Cucumber Pollen Sterile Mutant: Inheritance, Allelism, and Response to Chemical and Environmental Factors
}

\author{
Qi Zhang', August C. Gabert ${ }^{2}$, and James R. Baggett ${ }^{3}$ \\ Department of Horticulture, Oregon State University, Agricultural and Life Sciences Building 4017, \\ Corvallis, OR 97331-7304
}

\begin{abstract}
Additional index words. Cucumis sativus, vegetable breeding, $\mathrm{F}_{1}$ hybrid
\end{abstract}
\begin{abstract}
A new sterile mutant designated pollen sterile (PS) found in pickling cucumber (Cucumis sativus L.) is characterized by normal corolla in staminate and pistillate flowers, normal fertility in the female, and absence of pollen in otherwise normal-appearing staminate flowers. All $\mathrm{F}_{1}$ plants from PS x male fertile (MF) sib-matings were MF, and $F_{2}$ progeny segregated $3 \mathrm{MF}: 1 \mathrm{PS}$. Sib-matings of PS segregates with sister MF segregates produced either $1 \mathrm{MF}: 1 \mathrm{PS}$ ratios or all normal plants. Thus, PS is controlled by a single recessive gene. The PS gene is not allelic to apetalous (ap), but was shown to be allelic to male sterile-2 $(m s-2)$ and is designated $m s-2^{\mathrm{ps}}$. It was not possible to determine possible allelic relationships between $m s-2^{\mathrm{rs}}$ and $m s-1$ because of strong male and female sterility of the available $m s-1$ material. $F_{1}$ generations from gynoecious-PS and monoecious-PS crossed with monoecious, gynoecious (silver-ion treated), and hermaphroditic parents produced no PS plants and sex types did not influence PS levels in $F_{2}$ progenies, indicating it is not possible to maintain the PS mutants through crosses with different cucumber sex types. It was not possible to change the expression of PS by applying cytokinin, IAA, or GA, and there were no changes in response to temperature and fertilizer treatment. Unlike gynoecy, which is responsive to some external factors, PS is unresponsive. The results suggest that the use of PS in cucumber $F_{1}$ hybrid seed production is not practical. Chemical names used: indole acetic acid (IAA), gibberellin (GA)
\end{abstract}

Male sterility (MS) is of practical importance in cucumber (Cucumis sativus $\mathrm{L}$.) breeding because it can facilitate $\mathrm{F}_{1}$ hybrid seed production without hand pollination. Five MS forms are known: 1) gynoecious (G) flowering; 2) an apetalous sterile mutant (ap); 3) a pleiotropic pollen-aborted mutant (ms-1);4) an aborted male flower type ( $m s-2)$; and 5) a closed-flower type.

The $\mathrm{G}$ character is under the control of several loci. Usually, $\mathrm{G}$ is considered to be a form of sex expression rather than MS because it is one of several sex segregates (Lower and Edwards, 1986; Pierce and Wehner, 1990).

In $a p$, the corolla lacks staminate and pistillate flowers, and anthers become sepal-like (Grimbly, 1980).

The recessive pleiotropic gene $m s-1$ determines MS in which failure of staminate flower anthesis and pollen sterility (PS) varies from 30\% to 90\% (Shifriss, 1950). Grimbly (1980) and Hutchins (1936) each reported that $m s-1$ conditions sterility in which staminate flowers are devoid of pollen, and fertility of pistillate flowers is decreased.

In $m s-2$, the MS plants are characterized by abortion of the staminate blossoms. In rare instances when the flowers matured to anthesis, only rudimentary anthers that contained no pollen were present (Barnes, 1960; Miller and Quisenberry, 1978; Whelan, 1974).

The closed-flower variant is controlled by a recessive gene $\mathrm{cl}$. Both staminate and pistillate flowers fail to open at maturity (Groff and Odland, 1963).

Received for publication 4 May 1993. Accepted for publication 7 Feb. 1994. Oregon Agricultural Experiment Station technical paper no. 9447. The cost of publishing this paper was defrayed in part by the payment of page charges. Under postal regulations, this paper therefore must be hereby marked advertisement solely to indicate this fact.

${ }^{1}$ Former graduate research assistant. Current address: Amsa Seed Co., P.O. Box 530, Modesto, CA 95352.

${ }^{2}$ Courtesy associate professor and plant breeder. Current address: SunSeeds Co., Brooks, OR 97305.

${ }^{3}$ Professor.
Except for G, these forms of MS have not been used in hybrid cucumber seed production because their inheritance is determined by nuclear genes and because they are associated with undesirable traits such as missing corolla, malformed ovary, and closed female flowers (Grimbly, 1980; Hutchins, 1936).

Many inbred lines were observed for sex expression and fertility at the SunSeeds Co. in Brooks, Ore. In 1988, a single MS plant was found in an inbred line, pedigree 23B-X26, which is of pickling type and is segregating for $\mathrm{G}$ flowering. The corolla of staminate and pistillate flowers of this mutant is normal and pistillate flowers are fertile. The staminate flowers are generally normal in appearance but have rudimentary anthers and produce no pollen. These mutant PS plants produce a few aborted flower buds only after they are loaded with fruit or they are physiologically mature. In the search for a suitable technique to maintain the PS mutant, it was hypothesized that it might be similar to certain sex types $[\mathrm{G}$, monoecious $(\mathrm{M})$, or hermaphroditic $(\mathrm{H})]$ in its sensitivity to some external factors, and that it might be maintained by a certain sex type or by selfing after restoring fertility by changing external factors.

The purpose of the present study was to determine 1) the genetic control of the PS mutant and possible allelic relationships with other known MS types (except $\mathrm{G}$ flowering and the closed-flower type), and 2) if the PS mutant could be induced to produce pollen in different sex expression backgrounds or by using chemical treatment or environmental modification.

\section{Materials and Methods}

Inheritance of the PS mutant. When the original PS plant was found, it was sib-mated (SB) with a male fertile (MF) plant of the same inbred line. Fourteen seeds $\left(\mathrm{SB}_{1}\right)$ from this $\mathrm{SB}$ were obtained from the mutant plant and were planted in the greenhouse. Each of the 14 seeds produced an MF plant. Each of these was selfed, and seeds from the 14 plants were bulked. Thirty-five progeny plants from this bulk population were grown, the PS segregates were SB 
with several randomly selected $\mathrm{MF}$ segregates $\left(\mathrm{MF}_{\mathrm{A}}, \mathrm{MF}_{\mathrm{B}}, \mathrm{MF}_{\mathrm{C}}\right.$, ...), and the MF segregates were selfed at the same time. However, only seven $\mathrm{SB}$ mutant plants and three $\mathrm{MF}$ plants $\left(\mathrm{MF}_{\mathrm{A}}, \mathrm{MF}_{\mathrm{B}}\right.$, and $\mathrm{MF}_{\mathrm{C}}$ ) produced enough selfed seeds to test. Seeds were harvested separately from each fruit of each mating.

During Summer 1989, all of the SB families were grown in the greenhouse. Forty seeds of each family were planted in seven 11.4liter pots filled with a standard commercial soil mix consisting of $70 \%$ bark materials, $30 \%$ soil, lime, complete fertilizer, and a wetting agent. The 10 families were randomly arranged in a greenhouse. Plants were irrigated and fertilized with an automatic drip system. No supplemental lighting was used.

Plants were classified as PS or fertile at anthesis according to the external appearance of anthers in the staminate flowers. A plant was classified as PS if it had open staminate flowers with aborted anthers on the first 10 nodes. Also, anthers periodically were observed without staining under a light microscope $(\times 40)$ for presence of pollen.

Allelism tests. Initially, tests for allelism with PS mutants were to include ap, $m s-1$, and $m s-2$. As described below, tests with ap and $m s-2$ were successfully completed. Tests with $m s-1$ were not possible because, in making the initial crosses to obtain plants heterozygous for this mutant, the sterility of the pistillate flowers of MS plants of the $m s-1$ parent (SunSeeds M line 22676-6) was much higher than that of staminate flowers, and no viable seeds were obtained.

For the test of allelism with $a p$, heterozygous Ap ap plants [obtained by crossing normal ( $A p A p$ ) plants with SunSeeds ap line 23BX75], were crossed with the PS mutant. Additionally, Ap Ap plants homozygous for PS were crossed with plants heterozygous (MF) for PS. To test for allelism with $m s$-2, PS mutant plants were crossed with plants heterozygous for $m s-2$ (obtained by crossing normal $M s-2 M s-2$ with SunSeeds $m s-2$ line 18849 x 23B-114-A). The $\mathrm{F}_{1}$ progenies from these crosses were planted in the greenhouses and fields of SunSeeds Co., Oregon State Univ. (OSU), and Amsa Seed Co. in Modesto, Calif., during Spring 1991 to Fall 1992.

The relationship of PS to sex types was studied as a component in an $\mathrm{AB}$ line consisting of half homozygous MS (A) and half heterozygous fertile (B) plants. Cucumber lines of three sex types-M-F-; G (SunSeeds 23-116), M-ff; M (SunSeeds 23-113), and mmFf; H (MSU-669H) —were also used.

Initially, the AB line was planted in 7011.4 -liter pots. When the flower buds could be identified, G plants were tagged and sprayed with a 500 ppm solution of silver thiosulfate. The PS plants in the $\mathrm{AB}$ line were classified into two types: 1) M-PS, which have anther-aborted male flowers and 2) G-PS, which have antheraborted sterile flowers after treatment with silver thiosulfate. After these PS plants were tagged, both types were moved to the greenhouse and crossed with $\mathrm{G}, \mathrm{M}$, and $\mathrm{H}$ plants to give the following combinations: 1) M-PS x M, 2) G-PS x M, 3) M-PS x G, 4) G-PS x G, 5) G-PS x H, and 6) M-PS x H. Seeds from each cross were bulked and planted in the greenhouse in Winter 1990. The $\mathrm{G} \mathrm{F}_{1}$ plants were treated with silver thiosulfate and the percentage of $G$ plants in each $F_{1}$ was recorded. The plants were also checked daily to determine if PS plants were present. During Spring 1991, $F_{2}$ populations from each cross were planted in the SunSeeds and OSU greenhouses (as two blocks) to determine the segregation of fertility types. $\mathrm{F}_{2}$ seed was produced by selfing $\mathrm{F}_{1}$ plants of the sex type shown in the parentheses in the following: M-PS x M (M), G-PS x M (M), M-PS x G (M), G-PS x G (G), G$P S \times H(G)$, and $M-P S \times H(M)$. The number of $F_{2}$ seeds from crosses $\mathrm{M}-\mathrm{PS} \times \mathrm{G}$ and $\mathrm{G}-\mathrm{PS} \times \mathrm{H}$ was not adequate for replication.
Therefore, an augmented randomized complete-block design (Federer, 1956), which involves replicated and unreplicated populations, was used for the six $\mathrm{F}_{2}$ populations. A replication for each treatment consisted of five pots and each pot contained 10 plants. The $\mathrm{G}$ plants were treated with silver thiosulfate to produce male flowers, and the MS plants were observed at anthesis. The percentages of PS plants were transformed by arcsin and tested by Fisher's protected LSD.

Hormone treatment and the flowering behavior of PS. Three levels for each of the hormones (kinetin, IAA, and $\mathrm{GA}_{3}$ ) were applied as a factorial set of 27 combinations arranged in a completely randomized block design with two replications. For each treatment combination and replication there were 50 plants in five pots. The bulked experimental seed from the AB line was divided into 54 parts and sprouted in petri dishes. Concentrations used were 0, 500, and $1500 \mathrm{ppm}$ for kinetin; 0, 100, and $200 \mathrm{ppm}$ for IAA; and 0,1 , and $10 \mathrm{mg} \cdot$ liter $^{-1}$ for $\mathrm{GA}_{3}$. The sprouted seeds were immersed in the assigned hormone solution for $24 \mathrm{~h}$, sown in pots, and moved to a greenhouse. Repeat applications were made by spraying seedlings with the respective hormone treatment when their cotyledons were completely unfolded and again when the fourth leaf was completely unfolded. At the same time, all of the plots were sprayed with silver thiosulfate to promote male flowers on the $\mathrm{G}$ plants. The proportion of PS plants was recorded when the fertility of male flowers could be determined.

Temperature and fertilizer level and performance of PS. To estimate the effects of temperature and fertilizer on PS, two levels of temperature, $\mathrm{N}, \mathrm{P}$, and $\mathrm{K}$ were tested on bulked seed from the $\mathrm{AB}$ line. Test plants were grown in two greenhouses: A) maintained at $13 \mathrm{C}$ night and $24 \mathrm{C}$ day, and B) maintained at 24C night and 32C day. Two replications of eight factorial combinations of two levels each of $\mathrm{N}$ ( 0 and $173 \mathrm{ppm}), \mathrm{P}(0$ and $39 \mathrm{ppm})$, and K (0 and 280 ppm) were used in each greenhouse. For each replication of each treatment, 50 seeds were planted in five sand-filled pots (10 seeds per pot), which were fertilized with the respective fertilizer combination in water solution. All plants were sprayed with silver thiosulfate three times to promote staminate flower production on the $\mathrm{G}$ plants. The flowers at the first few nodes of each plant were observed for the expression of MS.

\section{Results and Discussion}

Inheritance of the PS mutant. All offspring of the original PS plant from $\mathrm{SB}_{1}$ were $\mathrm{MF}$ (Table 1). Segregation among the $30 \mathrm{~F}_{2}$ plants produced from these $\mathrm{SB}_{1}$ plants closely fit the expected 3 MF : 1 MS ratio.

Among the three families from selfed $\mathrm{MFF}_{2}$ plants, the families from plant $\mathrm{MF}_{\mathrm{A}}$ and $\mathrm{MF}_{\mathrm{C}}$ segregated $3 \mathrm{MF}$ : $1 \mathrm{MS}$, while the family from plant $\mathrm{MF}_{\mathrm{B}}$ had only MF progeny.

Four $\mathrm{F}_{3}$ families derived from test crossing $\mathrm{MF}$ plants $\mathrm{MF}_{\mathrm{A}}$ and $\mathrm{MF}_{\mathrm{C}}$ with sister PS plants segregated in the expected $1 \mathrm{MF}: 1 \mathrm{MS}$ ratio. The families involving plant $\mathrm{MF}_{\mathrm{B}}$ as pollen parent produced only MF plants. These data indicate that $\mathrm{MF}_{\mathrm{A}}$ and $\mathrm{MF}_{\mathrm{C}}$ in the $\mathrm{F}_{2}$ generation were heterozygous for $\mathrm{MS}$ and that $\mathrm{MF}_{\mathrm{B}}$ was homozygous.

Additional genetic data were provided by the crosses made to determine the relationship between PS and sex types. There were no PS plants in the $F_{1}$ progenies when $M$ and $G$ PS plants were crossed with MF-M plants or $\mathrm{G}$ plants treated with silver thiosulfate (Table 2). Ratios of MF : MS plants in the $\mathrm{F}_{2}$ progenies of these crosses closely fit the $3: 1$ ratio expected for recessive monogenic inheritance (Table 3).

Genetic relationship of the PS mutant to ap and $m s-2$. Each of 
Table 1. Inheritance of a pollen sterile mutant in cucumber.

\begin{tabular}{|c|c|c|c|c|c|}
\hline \multirow[b]{3}{*}{ Generation $^{y}$} & \multirow{3}{*}{$\begin{array}{l}\text { Source of } \\
\text { families }\end{array}$} & \multicolumn{2}{|c|}{ Segregation } & & \\
\hline & & \multirow{2}{*}{$\begin{array}{c}\text { Male } \\
\text { fertile }(\mathrm{MF})\end{array}$} & \multirow{2}{*}{$\begin{array}{l}\text { Male } \\
\text { sterile }\end{array}$} & \multicolumn{2}{|c|}{$\chi^{2 \mathrm{z}}(P)$} \\
\hline & & & & $3: 1$ & $1: 1$ \\
\hline $\mathrm{SB}_{1}$ & & 14 & $--^{x}$ & --- & --- \\
\hline $\mathrm{F}_{2}$ & & 23 & 7 & $0.04(0.90-0.50)$ & --- \\
\hline \multirow{3}{*}{$\mathrm{F}_{3}^{2}$} & $\mathrm{MF}_{\mathrm{A}}$ selfed & 25 & 9 & $0.04(0.90-0.50)$ & \\
\hline & $\mathrm{MF}_{\mathrm{B}}^{\mathrm{A}}$ selfed & 28 & 0 & -- & --- \\
\hline & $\mathrm{MF}_{\mathrm{C}}^{\mathrm{D}}$ selfed & 28 & 6 & $0.63(0.50-0.10$ & --- \\
\hline \multirow[t]{7}{*}{$\mathrm{SB}_{2}$} & $1 \times \mathrm{MF}_{\mathrm{C}}$ & 22 & 14 & --- & $1.36(0.50-0.10)$ \\
\hline & $2 \times \mathrm{MF}_{\mathrm{C}}$ & 21 & 19 & --- & $0.03(0.90-0.50)$ \\
\hline & $5 \times \mathrm{MF}_{\mathrm{C}}$ & 11 & 17 & --- & $0.89(0.95-0.10)$ \\
\hline & $2 \times \mathrm{MF}_{\mathrm{A}}$ & 17 & 20 & --- & $0.11(0.90-0.50)$ \\
\hline & $2 \times \mathrm{MF}_{\mathrm{B}}^{\mathrm{A}}$ & 24 & 0 & --- & --- \\
\hline & $5 \times \mathrm{MF}_{\mathrm{B}}$ & 36 & 0 & --- & --- \\
\hline & $7 \times \mathrm{MF}_{\mathrm{B}}$ & 32 & 0 & --- & --- \\
\hline
\end{tabular}

${ }^{\mathrm{z}}$ All $\chi^{2}$ values are nonsignificant at $P=0.05$.

${ }^{\mathrm{y}} \mathrm{SB}_{1}$ derived from sib-mating the original pollen sterile plant with an MF sister; $\mathrm{F}_{2}$ derived from selfing $\mathrm{SB}_{1}$ plants; $\mathrm{F}_{3}$ derived from selfing three $M F F_{2}$ plants; $\mathrm{SB}_{2}$ progeny derived from sib-mating $\mathrm{PS} \mathrm{F}_{2}$ plants 1, 2, 5, and 7 with $\mathrm{MF} \mathrm{F}_{2} \mathrm{plants}_{\mathrm{MF}_{\mathrm{A}}}, \mathrm{MF}_{\mathrm{B}}$, or $\mathrm{MF}_{\mathrm{C}}$. Each combination listed in the $\mathrm{SB}_{2}$ represents seed from an individual fruit.

${ }^{x}$ Not tested.

Table 2. Occurrence of pollen sterility (PS) and sex type in $\mathrm{F}_{1}$ populations derived from crossing male sterile (MS) and fertile plants of different sex types [monoecious $(\mathrm{M})$, gynoecious $(\mathrm{G})$, hermaphroditic $(\mathrm{H})]$.

\begin{tabular}{lrcc}
\hline & \multicolumn{3}{c}{ No. of plants observed } \\
\cline { 2 - 4 } Cross & M & G & PS \\
\hline M-PS x M & 44 & 0 & 0 \\
G-PS x M & 30 & 5 & 0 \\
M-PS x G & 38 & 0 & 0 \\
G-PS x G & 2 & 27 & 0 \\
G-PS x H & 0 & 35 & $0^{z}$ \\
M-PS x H & 30 & 0 & $0^{z}$
\end{tabular}

${ }^{\mathrm{z}}$ There were two MS flowers on the first male node of two plants, two MS flowers on the first two male nodes of one plant.

yThere was one PS flower on the first male node of one plant.

the allelism test crosses involving ap plants produced $\mathrm{F}_{1}$ plants that were all MF (Table 4). The absence of $\mathrm{MS} \mathrm{F}_{1}$ plants indicates that our PS mutant is not allelic to ap.

Test crosses between the PS mutant and $M s-2 m s-2$ produced $126 \mathrm{MF}$ : $118 \mathrm{MS}$ plants (Table 4), which closely fits a 1:1 ratio and indicates that our mutant is allelic to $m s-2$. The allele controlling the occurrence of PS was designated as $m s-2^{\mathrm{ps}}$.
Relationship of PS to sex types. When six $\mathrm{F}_{1}$ progenies obtained by crossing M-PS or G-PS plants with M, G, or H were observed, no typical PS plants were found.

M-PS x M, M-PS x G, and M-PS x H F plants were all M; GPS $\times \mathrm{MF}_{1}$ plants were $30 \mathrm{M}: 5 \mathrm{G}$; G-PS $\times \mathrm{G} \mathrm{F}_{1}$ plants were $2 \mathrm{M}: 27$ $\mathrm{G}$; and $\mathrm{G}-\mathrm{PS} \times \mathrm{HF}_{1}$ plants were all $\mathrm{G}$ (Table 2). A few (one to four) MS flowers were found on the first four nodes of four plants in the $\mathrm{F}_{1}$ progenies from $\mathrm{G}-\mathrm{PS} \times \mathrm{H}$ (after silver-ion treatment) and M-PS $x H$. These results indicate that there is no possibility of using any of the three cucumber sex types to maintain the PS character.

When the $\mathrm{F}_{2}$ generations were observed under greenhouse conditions, the percentage of PS plants ranged from 18 to 32 (Table 3). All comparisons, which included blocks (two greenhouses), crosses, male parent effects, and female parent effects, were nonsignificant. $\mathrm{F}_{2}$ results support the conclusions that PS is not related to the known kinds of cucumber sex expression.

Effect of hormone treatment on the expression of PS. Treatments of the $\mathrm{AB}$ line with 27 factorials of three combinations each of IAA, $\mathrm{GA}_{3}$, and kinetin had no effect on the occurrence of PS in the progeny of the AB line (data not presented). All three levels of each hormone (including the $0 \mathrm{ppm}$ control) produced $\approx 50 \% \mathrm{PS}$ plants (main effects), the expected ratio of PS plants from the AB line. It was not possible to determine whether there was an

Table 3. Occurrence of pollen sterility (PS) in the $\mathrm{F}_{2}$ generation of crosses between cucumber sex types [monoecious (M), gynoecious $(\mathrm{G})$, hermaphroditic $(\mathrm{H})]$.

\begin{tabular}{lccccc}
\hline \hline & \multicolumn{5}{c}{ No. of plants observed $^{\text {z }}$} \\
\cline { 2 - 6 } Cross $^{\text {y }}$ & Total & Male fertile & PS & $\chi^{2} 3: 1$ & 0.14 \\
\hline M-PS x M (M) & 86 & 66 & 20 & 0.18 & $0.90-0.50$ \\
G-PS x M (M) & 66 & 48 & 18 & 0.35 & $0.90-0.50$ \\
M-PS x G (M) & 39 & 31 & 8 & 0.29 & $0.90-0.50$ \\
G-PS x G (G) & 114 & 88 & 26 & 1.63 & $0.90-0.50$ \\
G-PS x H (G) & 66 & 45 & 21 & 0.12 & $0.50-0.10$ \\
M-PS x H (M) & 78 & 59 & 19 & $0.90-0.50$
\end{tabular}

${ }^{\bar{Z}}$ Parent effects on percentage of PS plants were contrasted in replicated and unreplicated populations in the augmented randomized complete-block design. Blocks (greenhouses), $\mathrm{F}_{2}$ populations, female parents ( $\mathrm{G}$ vs. $\mathrm{M}$ ), and male parents ( $\mathrm{G}$ vs. $\mathrm{M}$ vs. $\left.\mathrm{H}\right)$ were all nonsignificant at $P=0.05$. Data from the two greenhouses are combined in this table.

yThe letter in parentheses indicates the sex type of the $F_{1}$ plant selfed to produce the $F_{2}$ seed. 
Table 4. Tests of allelism of the pollen sterile (PS) mutant with $A p$ (apetalous) and $M s$-2 (male sterile-2) in cucumber.

\begin{tabular}{|c|c|c|c|}
\hline \multirow[b]{2}{*}{$\begin{array}{l}\text { Cross } \\
\text { description }\end{array}$} & \multicolumn{3}{|c|}{ No. and genotype of $F_{1}$ plants } \\
\hline & $\begin{array}{l}\text { Male fertile } \\
\text { (MF) }\end{array}$ & $\begin{array}{l}\text { Male sterile } \\
\quad(\mathrm{MS})\end{array}$ & $\begin{array}{c}\chi^{2} \\
1: 1\end{array}$ \\
\hline $\begin{array}{l}\mathrm{PS}\left(A p A p m s-2^{\mathrm{PS}} m s-2^{\mathrm{PS}}\right) \\
\quad \mathrm{x} \text { heterozygous apetalous (Ap ap } M s-2 M s-2)\end{array}$ & $\begin{array}{c}255 \\
A p-M s-2 m s-2^{\mathrm{Ps}}\end{array}$ & 0 & \\
\hline $\begin{array}{l}\text { Apetalous (ap ap } M s-2 M s-2) \\
\left.\quad \times \text { heterozygous PS (Ap Ap Ms-2 } m s-2^{\mathrm{PS}}\right)\end{array}$ & $\begin{array}{c}115 \\
\text { Ap ap } M s-2\end{array}$ & 0 & \\
\hline $\begin{array}{l}\text { PS } m s-2^{\mathrm{PS}} m s-2^{\mathrm{PS}} \\
\quad \mathrm{x} \text { heterozygous MS }(M s-2 m s-2)\end{array}$ & $\begin{array}{c}126 \\
M s-2 m s-2^{\mathrm{PS}}\end{array}$ & $\begin{array}{c}118 \\
m s-2 m s-2^{\mathrm{Ps}}\end{array}$ & $0.26^{\mathrm{y}}$ \\
\hline
\end{tabular}

${ }^{\mathrm{z}}$ Genotypes of parents and $\mathrm{F}_{1}$ progenies and the symbol $m s-2^{\mathrm{PS}}$ for PS are based on the results of the tests.

yThe $\mathrm{c}^{2}$ value of 0.26 indicated a nonsignificant deviation from the expected $1 \mathrm{MF}: 1 \mathrm{MS}$ ratio at $P=0.05$.

interaction between hormone treatments and silver thiosulfate applied to induce male flowering in $\mathrm{G}$ plants.

Effect of temperature and fertilizer level on the expression of $P S$. The analysis of variance of the results obtained from two temperature levels and two levels each of N, P, and K showed no individual treatment effects or interactions (data not shown). The percentage of PS was always very close to 50 .

The lack of any influence of the hormone and fertilizer levels applied indicate that PS is very stable and unlikely to be influenced in its expression by external factors. Thus, it cannot be made fertile by environmental manipulation for maintenance. PS was not affected by sex type, so it cannot be maintained by $\mathrm{H}$ lines, as is possible with the $\mathrm{G}$ character.

The use of $\mathrm{AB}$ lines possessing $\mathrm{PS}$ is not practical for $\mathrm{F}_{1}$ hybrid seed production and as such is not an economical management tool. While PS lines could be maintained by tissue culture, this method is not as economical as the use of G lines. Thus, it seems that the PS mutant described here, as is the case with other cucumber MS forms reported, has little practical use at this time.

\section{Literature Cited}

Barnes, W.C. 1960. A male sterile cucumber. Proc. Amer. Soc. Hort. Sci. 77:415416.

Federer, W.T. 1956. Augmented (or Hoonuiaku) designs. Hawaiian Planters' Record 55:191-208.

Grimbly, P.E. 1980. An apetalous male sterile mutant in cucumber. Cucurbit Genet. Coop. Rpt. 3:9.

Groff, D. and M.L. Odland. 1963. Inheritance of closed-flower in the cucumber. J. Hered. 54:191-192.

Hutchins, A.E. 1936. The inheritance of green flowered variation in Cucumis sativus L. Proc. Amer. Soc. Hort. Sci. 33:513.

Lower, R.L. and M.D. Edwards. 1986. Cucumber breeding, p. 173-207. In: M.J. Bassett (ed.). Breeding vegetable crops. AVI, Westport, Conn.

Miller, Jr., J.C. and J.E. Quisenberry. 1978. Inheritance of flower bud abortion in cucumber. HortScience 13:44-45.

Pierce, L.K. and T.C. Wehner. 1990. Review of genes and linkage groups in cucumber. HortScience 25:605-615.

Shifriss, O. 1954. Male sterilities and albino seedlings in Cucurbits. J. Hered. 36:47-52.

Whelan, E.D.P. 1974. Linkage of male sterile, glabrate seedling, and determinate plant habit in cucumber. HortScience 9:576-577. 